\title{
Towards a Research Training Curriculum: What, why, how, who? ${ }^{1}$
}

\author{
Paper accepted for Australian Educational Researcher: Special Issue: Reclaiming \\ Knowledge through Research Training
}

\author{
McWilliam, E., \& Singh, P. (2002). Towards a research training curriculum: What, why, \\ how, who? Australian Educational Researcher, 29(3), 4-18.
}

\begin{abstract}
:
Our purpose in this paper is to investigate the ways in which the work of research higher degree supervision is being reshaped from within and outside universities. Our interest is in the means by which new 'content' and 'process' knowledge - and thus a new set of pedagogical tasks and relationships - are being configured in the field of higher degree research. The outcomes of research training have traditionally been products of a one-on-one supervisory relationship, that is, academic apprentice-to-disciplinary mentor. This is especially the case in the fields of arts/humanities. Any 'curriculum' necessary to such a model has been both implicit and at the discretion of the disciplinary 'master'.
\end{abstract}

The paper maps the reasons that this model is being challenged, the policy and other mechanisms that are representing this challenge, the new modes of conduct and the new knowledge being produced by these policies and mechanisms, and the new pedagogical identities being forged as a result. We argue that the know-how of the academic supervisor is no longer coterminous with research training as 'expert' work. While disciplinary knowledge will continue to be important, and while one-on-one supervisory relationships will remain, they are unlikely to dominate the new higher degree research training landscape. New modes of knowledge production and new organisational arrangements are demanding different knowledge - less certain, less discipline specific - and different work - more teambased, more trans-disciplinary, and more accountable.

'Curriculum' is a term usually associated with coursework degrees rather than with higher degree research (HDR). This may be because curriculum's imperative to contain knowledge is widely understood to be contrary to the imperative of research to discover new knowledge. If, as Gibbons (2000) puts it, research is 'inherently transgressive', constantly spilling out of its institutional setting, 'embracing then discarding expertise' (p.357), and if curriculum is a means of containing knowledge by prescribing and thereby de-limiting what counts as worthwhile learning in a particular disciplinary field, then it is understandable that research and curriculum should stand apart from each other. However, it can probably be argued more convincingly that actual research, especially in the social or human sciences, is more prescriptive than transgressive (see Silva and Slaughter 1984, Haskell 1984). Thus the idea of a curriculum that guides individuals in enacting research need not be contradictory. Whether or not 'curriculum is only for coursework' has been the common sense of higher education pedagogy, it is clear that there is now a strong press to think curriculum as a necessary part of research. This, we argue, is an effect produced by new articulations of the nature and purposes of research training and supervision, and it is these new articulations we bring forward for scrutiny.

In what follows, we examine the means by which a higher degree research curriculum is being produced in Australian universities. Of particular interest is how rationalities emanating from government, the 'knowledge society', and organisational logic are rendering the processes and products of higher degree research more calculable to stakeholders within and outside university settings. That is, we are interested in how the conduct of higher degree research is being changed through imperatives geared towards making this area of university activity more nationally relevant, more quantifiable and thus more accountable for its outcomes.

Our examination is conducted in four parts. It begins with a delineation of the Australian federal government policies on HDR training (DETYA 2001b, Kemp 1999a, 1999b). The 
training imperatives which arise out of this agenda are theorised by drawing on emergent conceptualisations of the knowledge (Leadbeater 1999) and/or informational economy (Castells 2000). The centrality of risk minimisation within this information economy is then taken up, with the fourth and final section of the paper being devoted to the ways in which both the content and the processes of research supervision are being reconstituted within Australian universities as risk-conscious, publicly accountable organisations.

\section{What and why: state policy and research training}

There is little doubt that 'postwelfare' governments, as buyers rather than patrons of higher education (McWilliam and O'Brien 1999), have turned the spotlight on higher degree research training as an area of university activity that has traditionally been conducted somewhat mysteriously behind the doors of the academic's private office. In Australia, the performance of higher degree research is now explicitly linked to a global knowledge economy, reduced state funding, increased public demands for higher levels of education, and mass enrolments of diverse student cohorts. This linking work has been done most effectively through the Department of Education, Training and Youth Affairs' (DETYA) discussion paper New Knowledge, New Opportunities (Kemp 1999a) and the policy statement Knowledge and Innovation (Kemp 1999b). Both the discussion and policy papers locate higher education research and research training as 'central to the Government's reforms of the higher education system' (Kemp 1999b, p. 3).

The reform agenda of these policy documents is based on a set of assumptions, namely that the Australian higher education research system has not been responsive to 'the rapid changes taking place in the way knowledge is being generated and applied' (Kemp 1999b, p. 3). The policy documents clearly link the rapid changes in knowledge generation and application to 'two great research-based technological revolutions: in information technology and in biotechnology' (Kemp 1999a, p. v). In this way the re-imagining and re-organisation of higher education is increasingly understood in terms of national interests in relation to global economic performance (DETYA 2001a, 2001b). On this point, the Knowledge and Innovation document (Kemp 1999b, p. 1) states:

Competition is strengthening on a global basis and Australia's competitiveness and attractiveness to investors is increasingly determined by our relative knowledge capabilities. Research - as a key source of knowledge and new ideas - is central to success in the global knowledge economy.

Having delineated this national imperative, the discussion and policy documents urge renewal of the higher education system in order to enhance Australia's 'global role as a creator and transmitter of knowledge' (Kemp 1999b, p. 3).

The training of HDR students receives particular attention in the Knowledge and Innovation policy statement. It is argued that research students constitute a major resource in terms of research productivity, academic renewal and dissemination of 'knowledge and skills within and between the research and wider communities' (Kemp 1999b, p. 17). The limitations or 'deficiencies in the current structure and performance of higher education research and research training' (Kemp 1999b, p. 2) include unacceptable waste of resources associated with long completion times and low completion rates among a longer list of concerns (Kemp 1999b, p. 2). These parallel some persistent concerns raised by users of research training, namely graduate students and industry employers' concerns regarding the 'quality and breadth of research training' (Kemp 1999a, p. 9). These groups are reported as being of the opinion that research training is often 'narrow and limiting in its specialisation; poorly supervised and out of line with the needs and expectations of employers' (Kemp 1999a, p. 9).

In order to redress these 'deficiencies' and 'reduce the high rates of drop-out and significant waste of both talent and investment' (DETYA 2000, p. 10), new models of government 
funding have been developed, models that drive reform by the logic of carrot and stick. Put in DETYA's terminology, the new financial frameworks have been designed precisely for 'recognise[ing] and reward[ing] those institutions that provide high-quality research training environments and support excellent and diverse research activities' (DETYA 2001b, p. 4). The effect is to render HDR programs operating within publicly funded universities more financially accountable to government as representative of the tax-paying public.

The significance of the performance-driven nature of these new funding arrangements is that they have had a very swift and telling impact on institutional arrangements for HDR training, so that it is now possible to claim that the measurement of HDR completions and progression rates has become part of the core administrative activity of all Australian universities (Considine, Marginson, Sheehan and Kummick 2001, DETYA 2001a). No longer would it be possible to treat research training as a sideline to a larger enterprise called research, nor would it be possible for the activities of research supervision to remain cloistered within the private rooms of the supervisor. Under the new performance-based funding imperatives, universities would have some autonomy and discretion in constituting HDR training policies and programs (DETYA 2000, 2001a, 2001b). However, they are increasingly under pressure to regulate the content and form of research training programs by:

- providing generic research and specialist disciplinary knowledge to larger cohorts of students;

- designing training programs for students who will develop research/knowledge careers in non-university settings;

- meeting the gap between public funding for universities and the demand for HDR places;

- seeking alternative funds for research deemed by the state to be non-priority, that is, not directly linked to nation capacity building (DETYA 2000, 2001a, 2001b).

The imperative to better (i.e. more efficiently) manage higher degree program funds in the context of substantial cuts to public funding support for universities has produced a strong call for universities to 'be highly business aware' (Considine et al. 2001, p. 32), and to focus more squarely on the needs and priorities of industry. While the imperative here is not a simple matter of the university operating as a business, nevertheless universities are to provide the public goods (education and training of knowledge workers) that underpin the production of private goods by other agents (Considine et al. 2001). In terms of HDR training this means ensuring that all students acquire the skills and knowledge to undertake research in diverse settings (including industry) and in the context of the new global knowledge economy (DETYA 2001a).

Thus, in addition to academic induction, research training now includes apprenticeship into commercial research, and has a very important additional role in offering training in advanced research to experienced workers in the knowledge economy. Where the original focus of research training was as a preparation for an academic career, there are now increasing applications of this type of HDR training to support the career development of knowledge workers (McWilliam et al. forthcoming). Entrants to such programs (e.g. professional doctorates) tend to be mid-career, while the focus of training is much more on what Boyer (1990) refers to as the scholarships of integration and application. This 'content' and rationale (the 'what' and the 'why' of curriculum) is now being authorised by both disciplinary and professional/industrial communities.

\section{What and why: knowledge society, social uncertainty and risk}

The 'what' and 'why' of a new research training curriculum has moved beyond knowledge production for academic apprenticeship not simply because of policy imperatives but for more profound reasons to do with the larger context in which HDR policy initiatives are being 
framed. The assertion that knowledge has replaced 'goods' as the dominant source of productivity and power in the $21^{\text {st }}$ century has quickly become almost clichéd. This is an effect of burgeoning interest in the work of a proliferation of theorists who have written about the nature of the knowledge society (Leadbeater 1999), the knowledge economy (Considine et al. 2001, Johnston 1998), or the informational society (Castells 2000). The key argument here is that, while knowledge production and use have been crucial driving factors in all societies, what sets the current context apart from former times is that 'knowledge is being applied to knowledge itself' (Drucker cited in Johnston 1998, p. 1). The two defining characteristics of the global knowledge economy are the increased knowledge intensity of the processes of creation, production and distribution of goods and services, and the fact that economic processes are becoming increasingly integrated via electronic connectivity on a global basis (Considine et al. 2001, Johnston 1998).

This growth in knowledge intensity in all areas of production, distribution and consumption has led to a growth in demand for 'knowledge workers' or 'symbolic analysts', that is, workers who are highly skilled in 'problem identification, problem solving and brokerage' (Johnston 1998, p. 3). These skills are highly prized because they are difficult to duplicate and cannot be managed through a command-control approach (Johnston 1998). Thus these skills are not likely to be developed out of traditional or disciplinary specific knowledge, because such 'scientific' knowledge is hierarchically organised as a coherent, explicit and systematically principled structure. Likewise, knowledge in the disciplinary fields of social science and humanities that 'takes the form of a series of specialised languages with specialised modes of interrogation and specialised criteria for the production and circulation of texts' (Bernstein 2000, p. 157), is unlikely in itself to be suited to the purposes of a new generation of symbolic analysts. Put another way, strongly insulated forms of singular disciplinary knowledge can no longer be sufficient to those HDR students who are seeking, (appropriately, according to government), to develop capacities and skills for use in professional and industrial settings (Singh et al. 2001).

The movement of HDR beyond academic apprenticeship is also an effect of an exponential growth in the volume and complexity of knowledge in practically every field of human endeavour and the electronic interconnectivity of knowledge-related industries (Castells 2000, Ungar 2000). Within such conditions, universities can no longer be the sole and/or key sites or institutions for the generation of new knowledge (Clark cited in Cowen 1996, Johnston 1998, Kemp 1999a). As Muller (2000, p. 147) argues:

the massification of higher education in the developed countries had by the 1960s and 1970s extruded an exponentially greater number of competent knowledgeable scientists and potential researchers than the traditional take-up capacity in the higher education institutions, traditional think-tanks and research and development laboratories could absorb. New forms of research-based bodies sprang up, in the private sector, in non-governmental organisations and in civic advocacy forums.

Moreover, the exponential growth in knowledge related industries has changed the social conditions in which knowledge as a commodity is produced, sold/distributed and consumed. Lyotard (1985) has described these times of hyper-knowledge productivity as performativity. Under conditions of performativity, Lyotard (1985) argues that knowledge ceases to be an end in itself. Knowledge is not pursued in a search for truth or greater understanding/meaning. Rather, the collapse of the legitimating principle which links science via philosophy to the discovery of truth permits a redefinition of traditional science (Lyotard 1985). According to Cowen (1996, p. 257):

The destruction of this legitimating principle permits the subjugation of science, the university and social systems to the principle of 'performativity'....If the metanarrative which links universities to a search for the truth and which places academics/intellectuals as the elite guardians of that narrative has broken down, then quality - defining it and establishing it - is a matter for managerial expertise. 
A further destabilising imperative has been the constitution of new modes of knowledge production, circulation and consumption as a result of the growth in knowledge industries (independent of, but networked with universities), as well as the conditions of hyperknowledge productivity. These new modes (described as Mode 2) complement rather than supplant disciplinary modes of knowledge (Mode 1). Gibbons et al. (cited in Johnston 1998, Hegarty 2000) distinguish between Mode 1 knowledge (disciplinary specific knowledge as described above) and Mode 2 knowledge. The second category of knowledge, Mode 2, is characterised as follows:

- problems substantially set and solved in the context of application;

- a transdisciplinary approach and resources;

- a heterogeneous set of skills and experience directed to knowledge production;

- weakly institutionalised, transient, and heterarchical organisational forms; and

- quality control not only through internal peer review, but also against a wider set of 'application' criteria reflecting the wider social composition of the interested audience (Johnston 1998, p. 16).

A further dimension to this new knowledge order is how both the volume and complexity of knowledge have escalated the entry and acquisition costs to every specialist knowledge domain. Universal or public access to state sponsored education does not imply universal acquisition of knowledge. As Ungar (2000, p. 299) has argued:

$[\mathrm{R}]$ esearch on the knowledge gap hypothesis reveals that prior knowledge in an area is critical to understanding and assimilating new information in that area. Starting with conceptual anchors for framing information, the gaining of knowledge in a field tends to follow a spiral model, with new bits added to prior accumulations. But the narrowing and differentiation of specialities means that the sheer number and diversity of conceptual anchors continue to multiply. As proliferating technical terms and ideas are overlaid with new facts and frequent revisions, speciality knowledge domains become forbidding to outsiders.

Alongside this proliferation of specialised knowledge there has been a paradoxical growth in ignorance or decrease in the 'degree of knowledge grasp' (Ungar 2000). In other words, the degree of knowledge grasp possible for an individual (i.e. the ratio of information the human intellectual can handle to the volume of information available) is quickly diminishing while the individual's degree of ignorance is on a steep upward curve (Ungar 2000).

All this is taking place in a set of social conditions described by Giddens (1990) as reflexive modernity, a period characterised by a loss of public trust in institutions and expert knowledge to solve human problems (see also above comments in relation to conditions of performativity). Increasingly, the very conditions of knowledge production, dissemination and consumption are being challenged. As Kenway (forthcoming, p. 7) puts it, the mood is to question: 'what is useful knowledge, how is it best produced, by whom and to what ends?'

Finally, despite the loss of legitimacy or certainty that increased knowledge production can solve human problems, there is an increased demand for more rather than less knowledge growth in order to arbitrate the growing uncertainty and complexity of everyday life (Muller 2000). It is important to note the ironic fact that the production of more knowledge does not lead to uncertainty reduction. Rather, it leads to heightened social indeterminacy and uncertainty (Jarvis 2000, Muller 2000). The term social indeterminacy describes new social conditions in which the exponential growth in the production and circulation of knowledge expands possibilities for self-determination, and at the same time leads to greater social 
complexity. Under these social conditions, the process of decision making for individuals and/or social groups becomes more risky and outcomes more uncertain (Nugent 2000).

\section{How and who: research training as risky business}

In a culture of knowledge productivity or performativity, non-completion and/or slow completion of HDR studies constitute a failure to perform. In other words, a university's investment in research training and supervision, that is, the investment of intellectual, social and material capital, has been poorly risk-managed in terms of HDR productivity outcomes. In this performance driven context, that is, a context of reduced state funding to universities, and increased demands for accessibility, accountability and productivity academics are being asked to consider the risks associated with enrolling HDR students. These risks materialise when students: (1) do not complete on-time; (2) fail to complete postgraduate work despite substantial investment of intellectual, social and material capital/resources, and/or (3) transfer to another institution during the period of candidature and thus transfer intellectual and social capital, as well as federal government funding awarded to institutions on the basis of HDR completions (Singh et al. 2001).

Concerns about the capacities of Australian universities to self-manage around such risks - to identify and minimise them - have been a theme of successive governments in recent times. They are made explicit in Michael Gallagher's (2000) summation of outcomes of discussions between the Australian Federal Government's Department of Education, Training and Youth Affairs (DETYA, now DEST) and senior university executives. Gallagher states that these discussions pointed to 'a number of failures' (p.38) that he links to the 'trial and error dimension' of university management practice to date. According to Gallagher, it is the lack of uniformity of practice within universities that is the key culprit in producing failure. 'The next phase of development', Gallagher concludes '....can be expected to be more formalised and professionally risk managed' (p.38). ${ }^{2}$

The professional management of risk demands knowledge of risk, and knowledge of risk produces new risks for the organisation and its personnel. As Ericson and Haggerty (1997) point out, the risk society is a knowledge society 'because scientific knowledge and technologies are sources of major risks and the primary basis of security efforts aimed at controlling such risks' (p.88). In Beck's (1992) terms, 'the sources of danger are no longer ignorance but knowledge....Modernity has become the threat and the promise of emancipation of the threat that creates itself' (p.183). So knowledge about risk is no escape from danger and uncertainty. Indeed such knowledge is itself dangerous. It threatens all professionals because it gives them processes for deciding what action to take and at the same time provides the means by which they can be found to have done the wrong thing (Ericson and Haggerty 1997, p. 89). Thus it is not simply that large populations of non-traditional clients have 'caused' a heightened vigilance in the university sector, just as it is not simply that the decline of the welfare state has 'caused' universities to become more accountable for the shrinking funding that they receive from governments, or that senior managers have 'caused' academics to spend more time in administration and less time in 'real' teaching. As necessary professional expertise, risk knowledge itself has within it the seeds of its own proliferation because it is both a means to manage uncertainty and danger, and constitutes uncertainty and danger to professionals everywhere.

Central to the 'negative' logic of risk management, as indicated above, is the idea that there must be more self-scrutiny, regularity and control within and across an organisational sector. This is manifested in an 'audit explosion' in universities (Strathern, 1997), as a defence against systemic arbitrariness. Audit mechanisms are designed to ensure organisational precision for coping with (appropriate) social imprecision. Put simply, the logic is that systems of management need to be uniform because individuals are not, nor are likely to be. This logic of procedural equity flies in the face of a more perverse reading of audit cultures as intentionally depersonalising. This is not to argue that such cultures do not have 
depersonalising effects. Rather, the point is that the logic of the intensive bureaucratic monitoring that is a feature of audit cultures is not simply 'one-size-fits-all' in terms of the individuals who are its 'products'. What is standard, however, is the particular model for measuring organisational performance. ${ }^{3}$

The introduction of audit mechanisms, whether as measurements of 'teaching effectiveness', or 'research quality', or 'accountability', has been for some time now a feature of a wide range of public and private universities (Shore and Wright 1999). Whether or not the appearance of these mechanisms heralds 'a new form of coercive and authoritarian governmentality' (Shore and Wright 1999, p. 1), the fact remains that managing the large and diverse student populations who are now engaging in university studies worldwide requires knowledge and activity that is outside the 'unique, informal culture' (Ericson and Haggerty 1997, p. 57) of academics' traditional work. Thus the craft knowledge of academics is being reshaped by administrative interventions that work to achieve fair and efficient institutional practice. It is not that academic knowledge is being displaced altogether. Rather it is being made over as 'professional expertise' through a process that Ericson and Haggerty (1997) describe thus:

[P]rofessionals obviously have 'know-how', [but] their 'know-how' does not become expertise until it is plugged into an institutional communication system. It is through such systems that expert knowledge becomes standardised and robust enough to use in routine diagnosis, classification, and treatment decisions by professionals (p.104).

The idea that academic work is being made the subject of 'routine diagnosis, classification, and treatment decisions' is often viewed as a sinister, Orwellian development in higher education, and particularly in HDR programs, with research supervision, once relatively ungovernable as 'private' pedagogical practice, increasingly risk managed through 'a system of regulatory measures intended to shape who can take what risks and how' (Hood et al. 1992, p. 136). For better and worse, HDR supervisors are being required to 'plug in' to audit technologies, those 'supremely reflexive' practices through which the university can make sense of itself as an organisation, can 'perform being an organisation through the act of selfdescription’ (Strathern 1997, p. 318).

\section{How and who: categories and cases of risk}

For organisations to become more visible to themselves (and thus more capable of selfregulating self-audit), it is necessary that expert knowledge become standardised and routinised so that it can be used to diagnose, classify and treat potential dangers within the organisation (Ericson and Haggerty 1997). This has the effect of changing the focus of professional service from the client to information about the client. Put another way, the target of practice is no longer an individual client, but factors which have been deemed by institutional policy to be those most liable to produce risk to the organisation. An effect of this, according to Robert Castel (1991), is the mutation of the practitioner-client relationship, so that the direct relation with the assisted subject that has characterised classical forms of professional intervention and service provision is transmuted into a relationship of practitioner-to-information. Castel (1991) elaborates:

The essential component of intervention no longer takes the form of the direct faceto-face relationship between the...professional and the client. It comes instead to reside in the establishing of flows of population based on the collation of a range of abstract factors deemed liable to produce risk in general...These items of information are then stockpiled, processed and distributed along channels completely disconnected from those of professional practice, using in particular the medium of computerised data handling (p. 281, p. 293, emphasis original). 
While Castel's theorising is focused on changing practices in the field of mental medicine and social work, there are, we suggest, clear parallels here with the changing nature of pedagogical work in research supervision and training. Academic supervisors are now required to pay close attention to the collation of a range of abstract factors that, when taken together, come to define a research degree candidate as a case of (more or less) potential risk. As within medical organisations, new preventive polices in universities serve to reconstruct HDR candidates, through statistical correlations of heterogeneous elements, as differentiated student population categories - part-time, off-campus, mature-aged, low SES, distance, as well as pre-confirmation, post-confirmation, pre-submission and so on - with each category requiring specific modalities of intervention (pedagogical/administrative) commensurate with the risks deemed to be associated with that population category. The 'how' of being an HDR supervisor is very much altered by this imperative.

Notwithstanding the primacy of the record over the student body, academics are to remain wedded to the idea of 'student or client-centredness'. 'Student-centredness' becomes a rationale for engaging closely with the individual student as a work-in-progress case compiled by the university's information managers (among whom they need to see themselves) and computer specialists. It is in this way that the university as a risk-conscious organisation is reconstituting the supervisor/student relationship, as one characterised neither by immediacy nor by the student as 'the concrete subject of intervention' (Castel 1991, p. 288). This makes for a very different enactment of the pedagogical relations of HDR from the traditional supervisor/student relationship. It is not that an individual academic must forego close personal relationships with students; however, the 'real work' is to demonstrate accountability by way of minimising risk and maximising quality in ways that are organisationally sanctioned and approved. Put bluntly, what really counts in the self-auditing university is the degree of intimacy and involvement an academic has with the record.

Concern with the record is more pronounced for HDR programs not simply because the most prestigious offerings in any university are to be found in higher degree research. It is also the fact that, where funding is focused on on-time completions, and where universities are penalised for 'losing' students, or for failing to assure quality (i.e. failing to monitor staff and student performance at all key 'transition' moments of the degree), the risk (of resource wastage) is increased. Thus 'good' academic supervisors come to engage more fully with the constantly changing technological communication and information processes of the university that focus on HDR management, rather than limiting their activities to in-house meetings with their 'real' students.

As Strathern (1997) avers, technology 'comes with the friendliest of epithets' (p.317) in the audit culture - the more of it used in ways that the organisation approves, the better. Thus the self-managing academic demonstrates improved teaching performance by pointing to the use of more and newer information communication technologies (ICTs). (The converse is also true - a teacher is unlikely to prove enhanced performance without this claim.) The number of 'hits' on websites can thus come to count as a measure of pedagogical effectiveness, just as the offering of subject content in multiple modes comes to count as a measure of the academic's capacity to be responsive to student diversity. In this culture, the work of intellectual provocation of students can appear to be of less consequence than the work of developing valid mechanisms for grading student performance, an issue which raises the ire of academics across the entire spectrum of teaching and supervision (Furedi 2002).

There is no doubting that a new research training 'curriculum' is producing its 'charming absurdities' (Hobart 1993) as audit meets academe. Strathern (1997) provides an example of such an absurdity when noting the concerns expressed by a 1992 Academic Audit Report on the performance on Cambridge University. The Report upbraided the University for not stating its 'aims and objectives'; for its 'informal and uncodified understanding about academic quality' and for the fact that 'the course and examination system does not lend itself 
to a tidy and straightforward procedure for programme design' (pp. 311-312). As Strathern notes, contradiction, conflict and maverick conduct seem to be as important to intellectual life as they are anathema to the audit exercise. In the singular consensus logic of audit, discontinuity prevents the organisation from being visible to itself and others - in Strathern's words, 'the auditors could not see how Cambridge University worked' (p.312).

Because audit cannot tolerate arbitrariness of any kind, whether useful to intellectual work or not, the audit culture has significant negative implications for those academic supervisors who seek a working life 'of lonely splendour' in which 'one...[is] able to come and go at one's

will' (Tierney 2001, p. 13). One of the most difficult issues for academics as research trainers is that it will no longer be possible to sit outside the performance culture and still do the work of research training. The option of 'just supervising' has been overtaken by the demands that all performance be accountable in terms of quality and that particular systems of communication and forms of documentation be engaged with for the distribution of performance-related knowledge. Likewise, the option of 'just researching' is sustainable only if the research is understood to be quantum-generating, with all of the processes of documentation and self-scrutiny that this involves. It is no accident that 'post-welfare' government policy-makers increasingly evoke the public interest in their calls for more guarantees that universities are 'performing'. In the logic of risk management, it is only possible to know that a university is performing its educative function properly if its workings are made visible on the brightly lit forensic table of audit.

\section{Conclusion}

We have argued that, for better and worse, the work of research training is being made calculable through a newly developing curriculum, one that is being shaped by developments both within and outside the academy. This curriculum - its rationale, its content, its pedagogy and its personnel - is constituted out of, and focused on, new modes of knowledge being produced in non-traditional ways by risk-conscious academic knowledge workers and nonacademic others who are seen to both represent and understand the demands of knowledge work in commercial settings. As a forensic, performance-driven imperative, the enactment of this new curriculum opens up new spaces for higher degree research as a pedagogical endeavour while leaving little space for any residual monasticism that might still be lurking in sandstone corridors.

\footnotetext{
${ }^{1}$ This paper builds on theoretical work undertaken in: Singh, P., McWilliam, E. \& Taylor, P. (2001) Knowledge Economy, Risk Society and Higher Degree Research Training Curriculum, in P. Singh and E. McWilliam, eds., Designing Educational Research: Theories, Methods and Practices, PostPressed, Flaxton.

${ }^{2}$ This finding is echoed in the Higher Education Management Review Committee in Australia (Hoare, Stanley, Kirkby and Coaldrake 1995) and in the Dearing Report (1997) in the United Kingdom. Both Committees foreground the failure of universities to develop the sort of management culture necessary to self-regulation in relation to organisational performance (see also DEST 2002a, 2000b)

${ }^{3}$ The value of feedback, for example, through a variety of evaluation instruments, is undisputed in regimes of self management, in that the seeking of feedback has all the appearance of being both voluntary and natural, rather than being a key site of worker contestation (Adkins and Lury 1999, p. $603)$.
} 


\section{References}

Adkins, L and C. Lury (1999) The labour of identity: performing identities, performing economies, Economy and Society, vol. 28, no. 4, pp. 598-614.

Beck, U. (1992) Risk Society: Towards a New Modernity, Sage, London.

Bernstein, B. (2000) Pedagogy, Symbolic Control and Identity, rev. ed., Rowman \& Littlefield, New York and Oxford.

Boyer, E. L. (1990) Scholarship reconsidered: priorities of the professoriate, Princeton, NJ.

Castel, R. (1991) From dangerousness to risk, in G. Burchell, C. Gordon and P. Miller, eds., The Foucault Effect: Studies in Governmentality, Harvester Wheatsheaf, London.

Castells, M. (2000) The Information Age. Economy, Society and Culture. Volume 1. The Rise of the Network Society, Blackwell, Oxford.

Considine, M., S. Marginson, P. Sheehan and M. Kummick (2001) The Comparative Performance of Australia as a Knowledge Nation. Report to the Chifley Research Centre, Monash Centre for Research in International Education, Melbourne.

Cowen, R. (1996) Performativity, Post-modernity and the University, Comparative Education, vol. 32, no. 2, pp. 245-258.

Dearing, R. (1997) Higher Education in the learning society: The National Committee of Inquiry into Higher Education, HMSO, London.

Department of Education, Science and Training (DEST) (2002a) Higher Education at the Crossroads, DEST, Canberra.

Department of Education, Science and Training (DEST) (2002b) Meeting the Challenges. The governance and management of universities, DEST, Canberra.

Department of Education, Training and Youth Affairs (DETYA) (2001a) Higher Education: Report for the 2001-2003 Triennium, DETYA Canberra.

Department of Education, Training and Youth Affairs (DETYA) (2001b) Research Training Scheme Guidelines, DETYA, Canberra.

Department of Education, Training and Youth Affairs (DETYA) (2000) Higher Education Report for the 2000-2002 Triennium, DETYA, Canberra.

Ericson, R.V. and K.D. Haggerty (1997) Policing the Risk Society, University of Toronto Press, Toronto.

Furedi, F. (2002) Consistency will mark end of initiative, The Australian, 17 July, p. 32.

Gallagher, M. (2000) The Emergence of the Entrepreneurial Public Universities in Australia. Paper presented at the IMHE General Conference of the OECD Paris, September, Occasional Paper Series 00/E, Commonwealth of Australia, DETYA.

Gibbons, M. (2000) Changing Patterns of University-Industry Relations, Minerva: A Review of Science, Learning and Policy, vol. 8, no. 2, pp. 352-361.

Giddens, A. (1990) The Consequences of Modernity, Polity Press, Cambridge.

Haskell, T., ed., (1984) The authority of experts: Studies in history and theory,. Indiana University Press, Bloomington, IN.

Hegarty, S. (2000) Teaching as a knowledge-based activity, Oxford Review of Education, vol. 26, no. 3/4, pp. 451-465.

Hoare, D. G. Stanley, R. Kirkby and P. Coaldrake (1995) Higher Education Management Review: The Report of the Committee of Inquiry, AGPS, Canberra.

Hobart, M., ed., (1993) An Anthropological Critique of Development: The growth of ignorance, Routledge, London.

Hood, C.C., D.K. Jones, B.A. Pidgeon, R. Gibson and others (1992) Risk Management, in Risk Analysis, Perception and Management, The Royal Society, Hertfordshire, pp. 135-201.

Jarvis, P. (2000) Globalisation, the learning society and comparative education, Comparative Education, vol. 36, no. 3, pp. 343-355.

Johnston, R. (1998) The Changing Nature and Forms of Knowledge: A Review, DETYA, Canberra.

Kemp, D. A. (1999a) New Knowledge, New Opportunities: A Discussion Paper on Higher Education Research and Training, AGPS, Canberra. 
Kemp, D. A. (1999b) Knowledge and Innovation: A Policy Statement on Research and Research Training, AGPS, Canberra.

Kenway, J. (forthcoming) Educational Research and Research Education in Australia, in S. Marginson and L. Manderson, eds., Postgraduate Training in the Social Sciences, Academy of the Social Sciences in Australia, Canberra.

Leadbeater, C. (1999) Towards the knowledge society, New Statesman, vol. 12, no. 563, pp. 25-27.

Lyotard, J. F. (1985) The Postmodern Condition: A Report on Knowledge, University of Minnesota Press, Minneapolis.

McWilliam, E., P.G. Taylor, P. Thomson, B. Green, T. Maxwell, H. Wildy and D. Simons (forthcoming) Research Training in Doctoral Programs: What can be learned from Professional Doctorates? Evaluation and Investigations Report, Department of Education, Science and Training, AGPS, Canberra.

McWilliam, E. and P. O'Brien (1999) Jonathan Livingstone, I presume: Teaching as a 'highflying' profession, Asia-Pacific Journal of Teacher Education, vol. 27, no. 2, pp. 95105.

Muller, J. (2000) Reclaiming Knowledge: Social Theory, Curriculum and Education Policy, Falmer, New York and London.

Nugent, S. (2000) Good risk, bad risk: Refexive modernisation and Amazonia, in P.Caplan, ed., Risk revisited, Pluto Press, London.

Shore, C. and S. Wright (1999) Audit Culture and Anthropology: Neo-Liberalism in British Higher Education, Journal of the Royal Anthropological Institute, vol. 5, no. 4, pp.557-576.

Silva, E. and S. Slaughter (1984) Serving power: The making of the academic social science expert, Greenwood Press, Westport, CT.

Singh, P., E. McWilliam and P. Taylor (2001) Knowledge Economy, Risk Society and Higher Degree Research Training Curriculum, in P. Singh and E. McWilliam, eds., Designing Educational Research: Theories, Methods and Practices, PostPressed, Flaxton.

Strathern, M. (1997) 'Improving ratings': audit in the British University system, European Review, vol. 5, no. 3, pp. 305-321.

Tierney, W. (2001) Academic Freedom and organizational identity, Australian Universities' Review, vol. 44, no.1-2, pp. 7-13.

Ungar, S. (2000) Risk-talk: The politics of risk and its representation, in P.Caplan, ed., Risk revisited, Pluto Press, London. 